\title{
Exploring the relationship between chronic undernutrition and asymptomatic malaria in Ghanaian children
}

\author{
Benjamin T Crookston ${ }^{1 *}$, Stephen C Alder ${ }^{1}$, Isaac Boakye ${ }^{2}$, Ray M Merrill ${ }^{3}$, John H Amuasi ${ }^{2}$, Christina A Porucznik', \\ Joseph B Stanford ${ }^{1}$, Ty T Dickerson ${ }^{4}$, Kirk A Dearden ${ }^{5}$, DeVon C Hale ${ }^{6}$, Justice Sylverken², Bryce S Snow ${ }^{1}$, \\ Alex Osei-Akoto ${ }^{7}$, Daniel Ansong ${ }^{7}$
}

\begin{abstract}
Background: A moderate association has been found between asymptomatic parasitaemia and undernutrition. However, additional investigation using the gold standard for asymptomatic parasitaemia confirmation, polymerase chain reaction (PCR), is needed to validate this association. Anthropometric measurements and blood samples from children less than five years of age in a rural Ghanaian community were used to determine if an association exists between chronic undernutrition and PCR-confirmed cases of asymptomatic malaria.

Methods: This was a descriptive cross-sectional study of 214 children less than five years of age from a community near Kumasi, Ghana. Blood samples and anthropometric measurements from these children were collected during physical examinations conducted in January 2007 by partners of the Barekuma Collaborative Community Development Programme.

Results: Findings from the logistic model predicting the odds of asymptomatic malaria indicate that children who experienced mild, moderate or severe stunting were not more likely to have asymptomatic malaria than children who were not stunted. Children experiencing anaemia had an increased likelihood (OR $=4.15 ; 95 \%$ Cl: 1.92, 8.98) of asymptomatic malaria. Similarly, increased spleen size, which was measured by ultrasound, was also associated with asymptomatic malaria ( $\mathrm{OR}=2.17 ; 95 \% \mathrm{Cl}: 1.44,3.28)$. Fast breathing, sex of the child, and age of the child were not significantly associated with the asymptomatic malaria.

Conclusions: No significant association between chronic undernutrition and presence of asymptomatic malaria was found. Children who experience anaemia and children who have splenomegaly are more likely to present asymptomatic malaria. Programmes aimed at addressing malaria should continue to include nutritional

components, especially components that address anaemia.
\end{abstract}

\section{Background}

More than half of child mortality related to major infectious diseases is attributed at least in part to undernutrition [1]. For many infectious diseases, such as acute lower respiratory infections, undernutrition is associated with risk of experiencing the infection in addition to the risk of dying from it [2-5]. In the case of malaria, which causes more than 200 million morbid episodes and more than one million child deaths each year, $57.3 \%$ of

\footnotetext{
* Correspondence: benjamin.crookston@utah.edu

'Department of Family and Preventive Medicine, University of Utah, 375
} Chipeta Way, Salt Lake City, UT 84108, USA deaths are attributed to undernutrition [6-10]. Further, undernutrition has been shown to impact both the manifestation of and susceptibility to malaria $[7,11]$.

Not all research, however, agrees that malaria and undernutrition have a synergistic relationship [9,12-14]. For example, several hospital-based studies suggest a protective effect against malaria for children experiencing protein energy malnutrition [15-17]. Other studies have shown similar protective effects against malaria for other forms of undernutrition [18,19]. Most recent research, though, indicates that undernutrition worsens malaria morbidity and mortality $[9,11,20-25]$. Further,

\section{() Biomed Central}


the causal relationship between undernutrition and malaria is a complicated one. On one hand, research shows that undernutrition increases susceptibility to malaria $[7,9]$. On the other, research indicates that malaria increases the likelihood of a child having poor nutritional outcomes [26-28]. Finally, most studies exploring the relationship between undernutrition and malaria have looked at symptomatic cases of malaria, leaving the relationship between asymptomatic cases of malaria and undernutrition often overlooked.

Malarial infection does not always result in symptomatic or overt disease. Children who experience malarial infection, but who do not exhibit acute symptoms, have asymptomatic parasitaemia, which is common in malaria endemic areas of sub-Saharan Africa, with some areas experiencing parasitaemia prevalence as high as $90 \%$ [29-34]. Most research thus far in the area of asymptomatic parasitaemia and undernutrition has pointed to an association between asymptomatic malaria and various measures of undernutrition [12,35-41], though some studies have found no association between undernutrition and asymptomatic malaria [42,43]. More research in this area, particularly research that uses polymerase chain reaction (PCR) testing to confirm parasitaemia in asymptomatic children, is needed.

This study took place in the country of Ghana, where malaria is endemic year round. With a total population of 23 million people, Ghana's health system reported more than 7 million cases of malaria during 2006 and is ranked $8^{\text {th }}$ out of the 19 countries estimated to have $90 \%$ of the cases in Africa [10,44]. Nearly one in seven cases required hospitalization and malaria accounts for $44 \%$ of all outpatients' visits in Ghana [45]. Further, malaria accounts for $13 \%$ of all hospital deaths and $22 \%$ of deaths in children less than five years of age in Ghana $[44,46]$. Finally, Plasmodium falciparum infections are estimated to account for approximately $10 \%$ of health life-years lost [47].

Anthropometric measurements and blood samples from children less than five years of age in a rural Ghanaian community was evaluated to determine if an association exists between chronic undernutrition (i.e. stunting) and PCR-confirmed cases of asymptomatic malaria. Further, the prevalence of stunting and asymptomatic malaria in addition to other basic physical examination findings is reported.

\section{Methods}

This study uses a cross-sectional design to evaluate the association between stunting and asymptomatic malaria. Data were obtained from physical examinations conducted by partners of the Barekuma Collaborative Community Development Programme (BCCDP). The $\mathrm{BCCDP}$ is a collaborative partnership between 20 rural
Ghanaian communities near Kumasi, Ghana and researchers from the Komfo Anokye Teaching Hospital (Kumasi, Ghana), the Kwame Nkrumah University of Science and Technology (Kumasi, Ghana), and the University of Utah (Salt Lake City, USA). The BCCDP, which began in 2001, uses a Community Based Participatory Research (CBPR) framework and serves approximately 25,000 people in 20 communities in a rural area approximately 25 kilometers north-west of Kumasi, the second largest city in Ghana [48]. Over the past seven years, partners from the BCCDP have worked with local community leaders to address health issues of concern to the community and partners, such as malaria, schistosomiasis, and diarrhoea. This has been accomplished through physical examination, disease surveillance, census registries, interviews, interventions and community development.

Near the beginning of the collaboration, community partners requested assistance addressing malaria and disease surveillance in the community. Researchers began by first assessing the burden of disease in partner communities. A pilot community was identified in which to conduct physical examination of children to identify common health problems. Data collection was specifically planned to address malaria. The results were intended to be used to inform programme and policy decisions, to test the specificity and sensitivity of a rapid diagnostic test, and to understand the interaction between malaria and other health outcomes in the study area.

Approximately 300 children from Adankwame and surrounding communities were brought by their guardians to the community center to receive a physical examination and to participate in the study. Notice of the study was given to all members of the communities involved and participation was voluntary. Blood samples and anthropometric measurements were available for 214 children less than five years of age.

University of Utah and local Ghanaian pediatricians performed physical examinations on children in the community of Adankwame during January of 2007. Community leaders and researchers encouraged mothers to bring children to the community center to receive the free physical examination. Children were examined on successive days. The physical examination included the collection of standard examination measures, such as age, height, weight, body temperature, pulse, blood pressure, spleen size. Additionally, blood, urine, and stool samples were also collected.

Field workers also gathered information from the child's caregiver on the recent health history of the child including data on recent febrile episodes and malaria symptoms. Binax $\mathrm{NOW}^{\circ}$ Malaria tests were used onsite. Blood smears to check for malaria parasites and complete blood counts were performed at the Komfo 
Anokye Teaching Hospital malaria laboratory. Additional laboratory work, including malaria PCR of blood smears, was completed at the University of Utah infectious diseases laboratory.

The primary outcome variable is a positive test for asymptomatic malaria parasitaemia. While rapid diagnostic malaria tests were conducted in the field, all blood samples were tested using PCR technology to confirm results from the field. No cases of symptomatic malaria were present in the sample.

Height-for-age $\mathrm{z}$-score (HAZ) was the primary predictor of interest. This measure is based on the international reference standard from Centers for Disease Control and Prevention and World Health Organization. The z-score is calculated through an interpolation function that accounts for sex, age, and height. A child with an HAZ greater than -1.0 standard deviations below the mean on the international reference standard was determined to have no stunting. Mild stunting is height-forage $\mathrm{z}$-score between -1.0 and -2.0 while moderate stunting is defined as a height-for-age $z$-score from -2.0 through -3.0. Severe stunting is defined as a height-forage $\mathrm{z}$-score less than -3.0 standard deviations below the mean on the international reference standard. Other physical examination characteristics examined included fast breathing, anaemia, and spleen size. Fast breathing was defined as greater than 50 breaths per minute in children 2-12 months and greater than 40 breaths per minute for children 12-60 months of age. Anaemia was defined as a child with a haemoglobin count of less than $11.0(\mathrm{~g} / \mathrm{dl})$. Lastly, spleen size was determined through the use of ultrasound.

All data were entered into the computer using Microsoft Excel (version 2003, Seattle, WA, USA). Statistical analyses were conducted using SAS statistical software (version 9.2, Cary, NC, USA). Anthropometric indicators were calculated using a SAS macro designed and made available by the World Health Organization (WHO). This macro uses the WHO International Growth Reference standard. Statistical analyses include a description of the characteristics of respondents. Additionally, percentages used to describe the population and to identify associations between undernutrition and presence of malaria were evaluated using Pearson chi-square tests. Further, prevalence of stunting by age groups was calculated. The relationship between height-for-age $\mathrm{z}$-score and the presence of asymptomatic malaria parasitaemia was analysed using logistic regression. Appropriate confounding variables that were available from physical examination data, such as age and sex, were retained or dropped from the models based on $\mathrm{p}$ values $(<.1)$ and conceptual considerations. Regression coefficients and $95 \%$ confidence intervals were calculated for retained variables. Interaction among confounders was also examined.
Research ethics approval was obtained in the US from the University of Utah and in Ghana from the Institutional Review Board of Kwame Nkrumah University of Science \& Technology School of Medical Sciences and Komfo Anokye Teaching Hospital. Informed consent was obtained from all household heads or guardians of the children enrolled in the study. Participation was voluntary and participants were able to withdraw at any time. Anti-malarials were provided to children who were found to have a positive test for malaria parasitaemia at the time of the physical examination. Children found to need treatment for some other problem were referred to a partnering Ghanaian physician and entered into the Ghana health care system.

\section{Results}

Children were fairly evenly distributed in each age group with four year olds making up the largest single group at $22.9 \%$ (Table 1 ). Nearly half $(48.1 \%)$ of all children were female. A majority of children experienced no

\section{Table 1 Children's characteristics}

\begin{tabular}{|c|c|}
\hline CHILD CHARACTERISTICS & $N=214$ \\
\hline \multicolumn{2}{|l|}{ Child age in years (\%) } \\
\hline$<1$ & 20.6 \\
\hline $1-1.9$ & 21.5 \\
\hline $2-2.9$ & 19.2 \\
\hline $3-3.9$ & 15.9 \\
\hline $4-4.9$ & 22.9 \\
\hline Sex, female (\%) & 48.1 \\
\hline \multicolumn{2}{|l|}{ Stunting ${ }^{1}(\%)$} \\
\hline None & 49.1 \\
\hline Mild & 31.3 \\
\hline Moderate & 13.6 \\
\hline Severe & 6.1 \\
\hline \multicolumn{2}{|l|}{ Asymptomatic Malaria (\%) } \\
\hline Yes & 31.8 \\
\hline No & 68.2 \\
\hline \multicolumn{2}{|l|}{ Fast Breathing ${ }^{2}(\%)$} \\
\hline Yes & 29.5 \\
\hline No & 70.5 \\
\hline \multicolumn{2}{|l|}{ Anaemia $^{3}(\%)$} \\
\hline Yes & 60.3 \\
\hline No & 39.7 \\
\hline
\end{tabular}


stunting $(49.1 \%)$ or mild stunting (31.3\%). Approximately one-third $(31.8 \%)$ of children were positive for asymptomatic parasitaemia. Lastly, $29.5 \%$ of children were diagnosed as fast breathing while $60.3 \%$ were determined to be anaemic.

The change in HAZ scores generally decreases the older the child was at the time of assessment (Figure 1). Median z-scores begin slightly above the mean reference for younger children and then begin to decline rapidly for each successively older group over the first 24 months of age. During the subsequent 36 months HAZ scores improve only slightly suggesting that children in this area experience little catch-up growth.

The percentage of positive cases of asymptomatic children appears to rise with age (Table 2). For example, of children who were positive for asymptomatic malaria, $10.3 \%$ were less than 1 year of age while $30.9 \%$ were between four and five years of age. The sex of the child was not significantly associated with asymptomatic malaria $(p=0.423)$. Further, stunting and fast breathing were not associated with whether or not a child was positive for asymptomatic malaria $(\mathrm{p}=0.519$ and $\mathrm{p}=$ 0.963, respectively). Finally, children who were anaemic were significantly more likely to be positive for asymptomatic malaria ( $\mathrm{p}<0.001)$. Specifically, $79.0 \%$ of asymptomatic cases were anemic while $51.2 \%$ of those who did not have asymptomatic malaria were anaemic.
Adjusted results for the logistic model predicting the probability of asymptomatic indicate that children who experienced mild, moderate or severe stunting were not more likely to have asymptomatic malaria than children who experienced no stunting (Table 3). Children experiencing anaemia had an increased odds of asymptomatic malaria. Similarly, increased spleen size was also associated with asymptomatic malaria. Fast breathing, sex of the child, and age of the child were not significantly associated with the asymptomatic malaria.

\section{Discussion}

These findings show no significant relationship between presence of asymptomatic malaria and stunting, a measure of chronic undernutrition. Children who were mildly stunted, however, appeared to be more likely to be asymptomatic than children who were not stunted, though the difference was not significant. This trend was not found for moderate and severely stunted children. Additionally, there is a strong relationship between anaemia and asymptomatic malaria as well as between spleen size and asymptomatic malaria. Lastly, findings indicate a general decline in median HAZ over the first 24 months of life followed by a leveling off and some subsequent recovery.

While other studies who have found an association between asymptomatic parasitaemia and undernutrition,

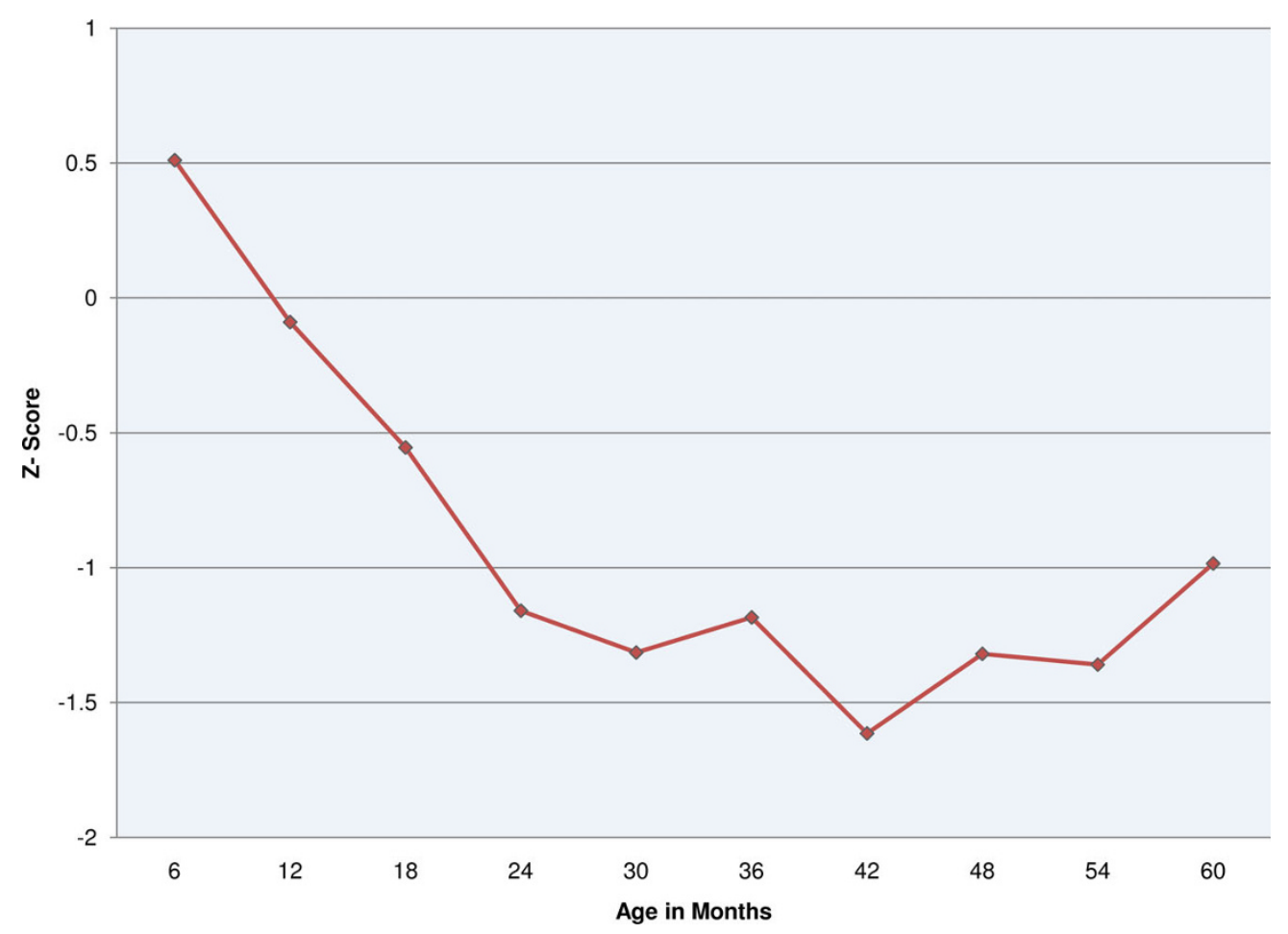

Figure 1 Median height-for-age z-scores by age. 
Table 2 Association between children's characteristics and asymptomatic malaria

\begin{tabular}{|c|c|c|c|}
\hline \multirow[b]{2}{*}{ Characteristics } & \multicolumn{2}{|c|}{ Asymptomatic Malaria } & \multirow[b]{2}{*}{$p$ value } \\
\hline & $\begin{array}{c}\text { Yes } \\
N=68\end{array}$ & $\begin{array}{c}\text { No } \\
N=146\end{array}$ & \\
\hline Child age in years (\%) & & & 0.029 \\
\hline$<1$ & 10.3 & 25.3 & \\
\hline $1-1.9$ & 20.6 & 21.9 & \\
\hline $2-2.9$ & 16.2 & 20.6 & \\
\hline $3-3.9$ & 22.1 & 13.0 & \\
\hline $4-4.9$ & 30.9 & 19.2 & \\
\hline Sex (\%) & & & 0.423 \\
\hline Female & 44.1 & 50.0 & \\
\hline Male & 55.9 & 50.0 & \\
\hline Stunting ${ }^{1}(\%)$ & & & 0.519 \\
\hline None & 44.1 & 51.4 & \\
\hline Mild & 38.2 & 28.1 & \\
\hline Moderate & 11.8 & 14.4 & \\
\hline Severe & 5.9 & 6.2 & \\
\hline Fast Breathing ${ }^{2}(\%)$ & & & 0.963 \\
\hline Yes & 29.7 & 29.4 & \\
\hline No & 70.3 & 70.6 & \\
\hline Anaemia ${ }^{3}(\%)$ & & & $<0.001$ \\
\hline Yes & 79.0 & 51.2 & \\
\hline No & 21.0 & 48.8 & \\
\hline
\end{tabular}

${ }^{1}$ Stunting: None $=-1 \leq \mathrm{z}$-score, Mild $=-2 \leq \mathrm{z}$-score $<-1$, Moderate $=-3 \leq \mathrm{z}$ score $<-2$, Severe $=z$-score $<-3$

${ }^{2}$ Fast Breathing: $>50$ breaths/minute for children 2-12 months, $>40$ breaths per minute for children 12-60 months

${ }^{3}$ Anaemia: $<11.0$ haemoglobin $(\mathrm{g} / \mathrm{dl})$

Table 3 Relations of stunting, anaemia and spleen size to asymptomatic malaria

\begin{tabular}{lccc}
\hline Independent Variable $^{\prime}$ & $\mathbf{N}$ & Odds Ratio & $\mathbf{9 5 \%} \mathbf{C l}$ \\
\hline Stunting & & & \\
$\quad$ None & 74 & 1.00 & - \\
$\quad$ Mild & 60 & 2.23 & $0.99,5.02$ \\
$\quad$ Moderate & 26 & 0.56 & $0.16,1.69$ \\
$\quad$ Severe & 12 & 1.02 & $0.20,3.76$ \\
& & & \\
Anaemia & \\
$\quad$ No & 74 & 1.00 & - \\
$\quad$ Yes & 98 & 4.15 & $1.92,8.98$ \\
& & & \\
Spleen Size & 172 & 2.17 & $1.44,3.28$ \\
\hline
\end{tabular}

${ }^{1}$ Stunting: None $=-1 \leq \mathrm{z}$-score, Mild $=-2 \leq \mathrm{z}$-score $<-1$, Moderate $=-3 \leq \mathrm{z}$ score $<-2$, Severe $=z$-score $<-3$

${ }^{2}$ Anaemia: $<11.0$ haemoglobin $(\mathrm{g} / \mathrm{dl})$

Variables not retained in the model: fast breathing, sex of child, age of child no such relationship was found in the study population. There could be a number of explanations for these differences. First, several studies found a relationship between asymptomatic parasitaemia and measures of undernutrition that did not include stunting $[13,35,39,41]$. Further, this study uses PCR, which is considered the gold standard for detection of malaria [49]. Studies that that did find an association with stunting and asymptomatic parasitaemia used a diagnostic method other than PCR [36-38]. Lastly, these results are consistent with studies that found no relationship between malaria infection and undernutrition $[40,42,43]$.

These findings indicating a strong association between presence of asymptomatic malaria and anaemia are consistent with findings from other studies that have linked malaria and anaemia [50-57]. Shankar reports that malaria is "the most significant human parasitic disease" and is a chief cause of anaemia [9]. Other research has shown that a solitary episode of uncomplicated malaria can cause mild anaemia [58]. While these results are not novel in this area, they do validate the data to some extent, thus strengthening the reliability of other findings.

Previous research indicates the key role the spleen plays in protection against malaria [59]. Increased spleen size was shown to be an important predictor of presence of asymptomatic malaria among children in our study. Other studies have shown similar associations with spleen size $[53,60]$. One study found spleen enlargement in $95-100 \%$ of individuals with malaria [59].

This study suffers from some limitations. First, a cross-sectional design was used, which cannot be used to infer causality, but should only used to identify associations. Second, the sample was a convenience sample of children, which may or may not be representative of the entire community or children from the country as a whole. Lastly, only physical examination and brief survey data were available. As a result, statistical models used for this study lack the ability to control for other potential confounders of the relationship between chronic undernutrition and asymptomatic malaria. For example, children from families with favourable economic circumstances may be less likely to be stunted in addition to having reduced exposure to malaria through the purchase and use of insecticide-treated bed nets.

\section{Conclusions}

In conclusion, no significant association between chronic undernutrition as measured by stunting and presence of asymptomatic malaria was found. This result does not suggest that no association exists between undernutrition and clinical malaria. Rather, it appears from these findings that malaria infection is not associated with chronic undernutrition. This is not 
incongruent with research that indicates that undernutrition may influence the burden of disease related to malaria or that clinical malaria may impact undernutrition [9]. Additionally, results are limited to chronic undernutrition. Measures of acute undernutrition, such as wasting or underweight may be more impacted by and provide more impact on asymptomatic malaria than chronic undernutrition. This relationship could not be explored with data presented here because the study population had very low rates of wasting and underweight. Research exploring the relationship between acute undernutrition and asymptomatic malaria is, therefore, needed. Finally, results do indicate that children who experience anaemia and children who have increased spleen size are more likely to be positive for asymptomatic malaria. Thus, programmes aimed at addressing malaria should continue to include nutritional components, especially components that address anaemia.

\section{Acknowledgements}

We acknowledge financial support from the University of Utah. We also thank Komfo Anokye Teaching Hospital and Kwame Nkrumah University of Science and Technology for technical and logistical support. We would like to especially thank Gladys Pomaah, administrative coordinator; David Sambian, lab technologist; Delanea Ocloo; and Naana Ayiwa Wireko Brobby for assistance in the collection of data. We also thank the mothers and children who willing gave of their time for this study.

\section{Author details}

'Department of Family and Preventive Medicine, University of Utah, 375 Chipeta Way, Salt Lake City, UT 84108, USA. ${ }^{2}$ Komfo Anokye Teaching Hospital, PO Box 1934, Kumasi, Ghana. ${ }^{3}$ Department of Health Sciences, Brigham Young University, 229 Richards Building, Provo, UT 84602, USA. ${ }^{4}$ Department of Pediatrics, University of Utah, 100 North Mario Cappechi Drive, Primary Children's Medical Center, Salt Lake City, UT 84113, USA. ${ }^{5}$ Department of International Health and Center for International Health and

Development, Boston University, 801 Massachusetts Avenue, Crosstown Center, 3rd Floor, Boston, MA 02118, USA. ${ }^{6}$ Department of Internal Medicine, School of Medicine 4C104, 30 N 1900 E, Salt Lake City, UT 84132, USA. ${ }^{7}$ Department of Child Health, School of Medical Sciences, Kwame Nkrumah University of Science and Technology, Kumasi, Ghana.

\section{Authors' contributions}

BTC conceived the study, performed the statistical analysis, and drafted the manuscript. SCA participated in the study design, helped develop the BCCDP, assisted in the data collection, and helped to draft the manuscript. IB participated in the data collection and revisions of the manuscript. RMM participated in the study design, assisted in analysis of data, and helped to draft the manuscript. JHA participated in the interpretation of results and the revision of the manuscript. CAP participated in the study design and helped to draft the manuscript. JBS participated in the study design and helped to draft the manuscript. TTD participated in the study design, interpreted the results, and helped to revise the manuscript. KAD participated in the study design, assisted in the data collection, and helped to draft the manuscript. DCH participated in the data collection, helped develop the BCCDP collaboration, and assisted with manuscript revisions. JS participated in the data collection, coordinated the physical examinations, and assisted with manuscript revisions. BSS assisted in the data analysis and manuscript revisions. AOA participated in the data collection, helped coordinate physical examinations, and assisted with manuscript revisions. DA participated in data collection, assisted with the coordination of physical examinations, coordinated the development of the BCCDP, and helped with manuscript revisions. All authors read and approved the final manuscript.

\section{Competing interests}

The authors declare that they have no competing interests.

Received: 8 September 2009

Accepted: 2 February 2010 Published: 2 February 2010

\section{References}

1. Caulfield L, Richard S, Rivera J, Musgrove P, Black R: Stunting, wasting, and micronutrient deficiency disorders. Disease Control Priorities in Developing Countries Washington, DC: Oxford University PressJamison D, Breman J, Measham A, Alleyne G, Claeson M, Evans D, Jha P, Mills A, Musgrove P , 2 2006, 551-567.

2. Black RE, Allen LH, Bhutta ZA, Caulfield LE, de Onis M, Ezzati M, Mathers C, Rivera J: Maternal and child undernutrition: global and regional exposures and health consequences. Lancet 2008, 371:243-260.

3. Fishman SM, Caulfield LE, de Onis M, Blossner M, Hyder AA, Mullany L, Black RE: Childhood and maternal underweight. Comparative quantification of health risks: global and regional burden of disease attributable to selected major risk factors Geneva: WHOEzzati M, Lopez AD, Rodgers A, Murray CJL 2004, 39-161.

4. Roth DE, Caulfield LE, Ezzati M, Black RE: Acute lower respiratory infections in childhood: opportunities for reducing the global burden through nutritional interventions. Bull World Health Organ 2008, 86:356-364.

5. Victora CG, Kirkwood BR, Ashworth A, Black RE, Rogers S, Sazawal S, Campbell $H$, Gove S: Potential interventions for the prevention of childhood pneumonia in developing countries: improving nutrition. Am J Clin Nutr 1999, 70:309-320.

6. Black RE, Morris SS, Bryce J: Where and why are 10 million children dying every year?. Lancet 2003, 361:2226-2234.

7. Caulfield LE, Richard SA, Black RE: Undernutrition as an underlying cause of malaria morbidity and mortality in children less than five years old. Am J Trop Med Hyg 2004, 71(Suppl 2):55-63.

8. Guinovart C, Navia MM, Tanner M, Alonso PL: Malaria: burden of disease. Curr Mol Med 2006, 6:137-140.

9. Shankar $\mathrm{AH}$ : Malaria and nutrition. Nutrition and Health in Developing Countries Totowa, NJ: Humana PressSemba RD, Bloem MW, second229-274.

10. World Health Organization, World malaria report 2008: Geneva: WHO 2008.

11. Shankar $\mathrm{AH}$ : Nutritional modulation of malaria morbidity and mortality. $J$ Infect Dis 2000, 182(Suppl):537-553.

12. Holding PA, Kitsao-Wekulo PK: Describing the burden of malaria on child development: what should we be measuring and how should we be measuring it?. Am J Trop Med Hyg 2004, 71:71-79.

13. Jeremiah ZA, Uko EK: Childhood asymptomatic malaria and nutritional status among Port Harcourt Children. East African Journal of Public Health 2007, 4:55-58.

14. Harrison GA, Waterlow JC: Diet and Disease in Traditional Developing Societies Cambridge: Cambridge Univ. Press 1990.

15. Edirisinghe J: Infections in the malnourished: with special reference to malaria and malnutrition in the tropics. Ann Trop Pediatr 1986, 6:233-237.

16. Goyal S: Protein energy malnutrition and cerebral malaria. J Trop Pediatr 1991, 37:143-144.

17. Hendrickse R, Hasan A, Olumide L, Akinkunmi A: Malaria in early childhood. Ann Trop Med Parasitol 1971, 65:1-20.

18. Genton B, Al-Yaman F, Ginny M, Taraika J, Alpers M: Relation of anthropometry to malaria morbidity and immunity in Papua New Guinean children. Am J Clin Nutr 1998, 68:734-741.

19. Nyakeriga AM, Troyo-Blomberg M, Chemtai AK, Marsh K, Williams TN: Malaria and nutritional status in children living on the coast of Kenya. Am J Clin Nutrition 2005, 80:1604-10, Erratun in Am J Clin Nutrition 2005, 82-203.

20. Deen $J$, Walraven $G E$, von Seidlein L: Increased risk for malaria in chronically malnourished children under 5 years of age in rural Gambia. J Trop Pediatr 2002, 48:78-83.

21. Ehrhardt S, Burchard GD, Mantel C, Cramer JP, Kaiser S, Kubo M, Otchwemah RN, Bienzle U, Mockenhaupt FP: Malaria, anemia, and malnutrition in African children-defining intervention priorities. $J$ Infect Dis 2006, 194:108-114. 
22. Galler JR, Barret LR: Children and famine: long-term impact on development. Ambulatory Child Health 2001, 7:85-95.

23. Takakura M, Uza M, Sasaki Y, Nagahama N, Phommpida S, Bounyadeth S, Kobayashi J, Toma T, Miyagi I: The relationship between anthropometric indicators of nutritional status and malaria infection among youths in Khammouane Province, Lao PDR. Southeast Asian J Trop Med Public Health 2001, 32:262-267.

24. Verhoef H, West C, Veenemans J, Beguin Y, Kok F: Stunting may determine the severity of malaria-associated anemia in African children. Pediatrics 2002, 110:E48

25. Williams T, Maitland K, Phelps L, Bennett S, Peto T, Viji J, Timothy R, Cleg J, Weatherall D, Bowden D: Plasmodium vivax: a cause of malnutrition in young children. QJM 1997, 90:751-757.

26. Frood JD, Whitehead RG, Coward WA: Relationship between pattern of infection and development of hypoalbuminaemia and hypo-beta-lipoprotinaemia in rural Ugandan children. Lancet 1971, 2:1047-1049.

27. Nyakeriga AM, Troye-Blomberg M, Chemtai AK, Marsh K, Williams TN: Malaria and nutritional status in children living on the coast of Kenya. Am J Clin Nutr 2004, 80:1604-1610.

28. Rowland MGM, Cole TJ, Whitehead RG: A quantitative study into the role of infection in determining nutritional status in Gambian village children. BrJ Nutr 1977, 37:441-450.

29. Bloland PB, Boriga DA, Ruebush TK, McCormick JB, Roberts JM, Oloo AJ, Hawley W, Lal A, Nahlen B, Campbell CC: Longitudinal cohort study of the epidemiology of malaria infections in an area of intense malaria transmission II: descriptive epidemiology of malaria infection and disease among children. Am J Trop Med Hyg 1999, 60:641-648.

30. Bottius E, Guanzirolli A, Trape JF, Rogier C, Konate L, Druilhe P: Malaria: even more chronic in nature than previously thought; evidence for subpatent parasitaemia detectable by thepolymerase chain reaction. Trans R Soc Trop Med Hyg 1996, 90:15-19.

31. Njama-Meya D, Kamya MR, Dorsey G: Asymptomatic parasitaemia as a risk factor for symptomatic malaria in a cohort of Ugandan children. Trop Med Int Health 2004, 9:862-868.

32. Rogier C, Trape JF: (Study of premunition development in holo- and meso-endemic malaria areas in Dielmo and Ndiop (Senegal): preliminary results, 1990-1994)(in French). Med Trop (Mars) 1995, 55:71-76.

33. Smith T, Charlwood JD, Kihonda J, Mwankusye S, Billingsley P, Meuwissen J, Lyimo $E$, Takken W, Teuscher T, Tanner M: Absence of seasonal variation in malaria parasitaemia in an area of intense seasonal transmission. Acta Trop 1993, 54:55-72.

34. Trape JF, Rogier C, Konate L, Diagne N, Bouganali H, Canque B, Legros F, Badji A, Ndiaye G, Ndiaye P, Brahimi K, Faye O, Druilhe P, Pereira de Silva L: The Dielmo project: a longitudinal study of natural malaria infection and the mechanisms of protective immunity in a community living in a holoendemic area of Senegal. Am J Trop Med Hyg 1994, 51:123-137.

35. Burgess HJ, Burgess AP, Driessen F: The nutritional status of children ages 0-5 years in Nkhotakota, Malawi. Trop Geogr Med 1975, 27:375-82.

36. Friedman JF, Kwena AM, Mirel LB, Kariuki SK, Terlouw DJ, PhillipsHoward PA, Hawley WA, Nahlen BL, Shi YP, ter Kuile FO: Malaria and nutritional status among pre-school children: results from cross-sectional surveys in western Kenya. Am J Trop Med Hyg 2005, 73:698-704.

37. Mamiro PS, Kolsteren P, Roberfroid D, Tatala S, Opsomer AS, Van Camp JH: Feeding practices and factors contributing to wasting, stunting, and iron-deficiency anemia among 3-23-month old children in Kilosa district, rural Tanzania. J Health Popul Nutr 2005, 23:222-230.

38. Renaudin P, Lombart JP: (Anemia in infants less than 1 year old in Moundou, Chad: prevalence and etiology)(in French). Med Trop (Mars) 1994, 54:337-42.

39. Sturchler D, Tanner M, Hanck A, Betschart B, Gautschi K, Weiss N, Burnier E, Del Giudice G, Degremont A: A longitudinal study on relations of retinol with parasitic infections and the immune response in children of Kikwawila village, Tanzania. Acta Trop 1987, 44:213-227.

40. Tshikuka J, Gray-Donald K, Scott M, Olela KN: Relationship of childhood protein-energy malnutrition and parasite infections in an urban African setting. Trop Med Int Health 1997, 2:374-382.

41. Wenlock RW: The epidemiology of tropical parasitic diseases in rural Zambia and the consequences for public health. J Trop Med Hyg 1979, 82:90-98.

42. Monjour L, Palminteri R, Froment A, Renault T, Alfred C, Gentilini M: Is cellmediated immune response related to nutritional state, but unaffected by concomitant malarial infection?. Ann Trop Med Parasitol 1982, 76:575-577.

43. Snow RW, Byass P, Shenton FC, Greenwood BM: The relationship between anthropometric measurements and measurements of iron status and susceptibility to malaria in Gambian children. Trans $R$ Soc Trop Med Hyg 1991, 85:584-589.

44. Roll Back Malaria, World Health Organization, United Nations Childrens Fund: World Malaria Report 2005 Geneva: WHO 2005.

45. De La Cruz N, Crookston B, Dearden K, Gray B, Ivins N, Alder S, Davis R: Who sleeps under bednets in Ghana: $A$ doer/non-doer analysis of malaria prevention behaviours. Malar J 2006, 5:61.

46. Abuaku BK, Koram KA, Binka FN: Antimalarial prescribing practices: A Challenge to Malaria Control in Ghana. Med Princ Pract 2005, 14:332-337.

47. Hyder AA, Rotllant G, Morrow RH: Measuring the burden of disease: healthy life-years. Am J Public Health 1998, 88:196-202.

48. Israel BA, Eng E, Schulz AJ, Parker EA: Introduction to methods in community-based participatory research for health. Methods in Community-Based Participatory Research for Health San Francisco, CA: JosseyBasslsrael BA, Eng E, Schulz AJ, Parker EA 2005, 3-26.

49. Johnston SP, Pieniazek NJ, Xayavong MV, Slemenda SB, Wilkins PP, da Silva AJ: PCR as a confirmatory technique for laboratory diagnosis of malaria. J Clin Microbiol 2006, 44:1087-1089.

50. Latham MC, Stephenson LS, Kinoti SN, Zaman MS, Kurz KM: Improvements in growth following iron supplementation in young Kenyan school children. Nutrition 1990, 6:159-65.

51. Menendez C, Kahigwa E, Hirt R, Vounatsou P, Aponte JJ, Font F, Acosta CJ, Schellenberg DM, Galindo CM, Kimario J, Urassa H, Brabin B, Smith TA, Kitua AY, Tanner M, Alonso PL: Randomised placebo-controlled trial of iron supplementation and malaria chemoprophylaxis for prevention of severe anaemia and malaria in Tanzanian infants. Lancet 1997, 350:844-50.

52. Premji Z, Lubega P, Hamisi Y, Mchopa E, Minjas J, Checkley W, Shiff C: Changes in malaria associated morbidity in children using insecticide treated mosquito nets in the Bagamoyo district of coastal Tanzania. Trop Med Parasitol 1995, 46:147-153.

53. Roshanravan B, Kari E, Gilman RH, Cabrera L, Lee E, Metcalfe J, Calderon M, Lescano AG, Montenegro SH, Calampa C, Vinetz JM: Endemic malaria in the Peruvian Amazon region of Iquitos. Am J Trop Med Hyg 2003, 69:45-52.

54. Shiff C, Checkley W, Winch P, Premji Z, Minjas J, Lubega P: Changes in weight gain and anaemia attributable to malaria in Tanzanian children living under holoendemic conditions. Trans R Soc Trop Med Hyg 1996, 90:262-265.

55. Stoltzfus RJ, Chwaya HM, Montresor A, Albonico M, Savioli L, Tielsch J: Malaria, hookworms and recent fever are related to anemia and iron status indicators in 0- to 5-y old Zanzibari children and these relationships change with age. J Nutr 2000, 130:1724-1733.

56. Verhoef H, West CE, Ndeto P, Burema J, Beguin Y, Kok FJ: Serum transferrin receptor concentration indicates increased erythropoiesis in Kenyan children with asymptomatic malaria. Am J Clin Nutr 2001, 74:767-775.

57. Yip R: Iron deficiency: contemporary scientific issues and international programmatic approaches. J Nutr 1994, 124:1479S-1490S.

58. Price RN, Simpson JA, Nosten F, Luxemburger C, Hkirjaroen L, ter Kuile F, Chongsuphajaisiddhi T, White NJ: Factors contributing to anemia after uncomplicated falciparum malaria. Am J Trop Med Hyg 2001, 65:614-622.

59. Zingman BS, Viner BL: Splenic complications in malaria: case report and review. Clin Infect Dis 1993, 16:223-232.

60. Genton B, Smith T, Baea K, Narara A, Al-Yaman F, Beck H-P, Hii J, Alpers M: Malaria: how useful are clinical criteria for improving the diagnosis in a highly endemic area?. Trans R SocTrop Med Hyg 1994, 88:537-541.

doi:10.1186/1475-2875-9-39

Cite this article as: Crookston et al:: Exploring the relationship between chronic undernutrition and asymptomatic malaria in Ghanaian children. Malaria Journal 2010 9:39. 